\title{
Impartation of Argumentation Skills: Impact of Scaffolds on the Quality of Arguments
}

\author{
Aviva Klieger, Amira Rochsar \\ Beit Berl College, Israel \\ Email: aviva.klieger@beitberl.ac.il
}

\begin{abstract}
Teaching via inquiry has been found to be a strategy suitable for the development of argument skills. The influence of the impartation of argumentation skills on the quality of the High school students' written argumentation was tested in the present study. Twenty written arguments in bio-inquiry papers were analysed by using two complementary tools: Toulmin's Argument Pattern to analyse the components and a modification of Toulmin's Argument Pattern to evaluate the quality of the written arguments. The various tools enabled us to pinpoint the differences between two groups: one group that did not receive scaffolds for constructing arguments and a group that received scaffolds for writing arguments. The findings indicate that impartation of argumentation skills improves the argumentation abilities and level. Students who received scaffolds for writing an argument wrote more and different types of arguments for each claim and wrote a higher quality argumentation in bio-inquiry papers.
\end{abstract}

Keywords: Argumentation; argument level; scientific inquiry; scaffolds

\section{Introduction}

Attempts have been made in recent years to implement curricula which focus on improving the argumentation ability (Efrat, 2002). The purpose of an argument is to afford an explanation, construct a model and develop a theory. Argumentation competence is among the goals of science education and has been studied extensively in science education (Erduran and Jimenez-Aleixandre, 2012; Erduran, Simon, \& Osborne, 2004; Kaya, Erduran, \& Seda-Cetin; Simon, Erduran, \& Osborne, 2006). The argumentation ability is an essential activity of scientists and is also among the goals of science education (Kaya et al. 2010, 2010; Simon et al. 2006). The argument is an important feature of science. It has therefore been studied extensively in science education (Erduran \& Jimenez-Aleixandre, 2008, 2012; Erduran et al. 2004; Jimenez-Aleixandre, Rodriguez, \& Duschl, 2000; Zohar \& Nemet, 2002).

This study examined the arguments written by twelfth-grade Israeli students in the discussion chapter of a bio-inquiry paper as part of their matriculation exam in biology. A comparison was made between the components, quality, and level of arguments written by students who did/did not receive scaffolds for acquiring argumentation skills during the course of the scientific inquiry.

\subsection{Inquiry and Argumentations}

Teaching through inquiry has been found to be a strategy for developing argumentation skills, under the assumption that the inquiry activity likens students' work to the work of scientists who are searching for answers to unclear phenomena and who want to propose explanations for them based on evidence (Wilson, Taylor, Kowalski, \& Carlson, 2010). Toulmin (1958) interpreted the term argument to mean a set of claims (C), data (D), warrants (W), backings (B), qualifiers (Q), and rebuttals (R). Toulmin's Argument Pattern (TAP) has been used extensively for coding arguments in different contexts, including texts, class discourse, and student lab reports. Argumentation can be defined as connections made between claims and data by using justification and evaluation of knowledge, since the construction of knowledge is also related to justification of this knowledge (Erduran \& Jimenez-Aleixandre, 2008, 2012). Zohar and Nemet (2002) defined an argument as consisting of justified assertions, conclusions, reasons, or supports (p. 38). Sampson and Clark (2008) indicated three issues that are critically 
important when studying how students generate arguments within the context of science: the structure or complexity of the argument, the content of the argument, and the nature of the justification.

Some application of TAP to science education has been made by collapsing problematic categories (data, warrants, and backings) and focusing on rebuttals (Erduran et al., 2004). Zohar and Nemet (2002) modified TAP to evaluate the quality of written arguments. Arguments are considered to be strong if they have multiple justifications for supporting a conclusion and incorporate relevant, specific, and accurate scientific concepts and facts. They also collapsed Toulmin's data, warrants, and backings into a single category in order to avoid the reliability and validity issues associated with Toulmin's framework.

In reviewing the literature, McNeill, Lizotte, Krajcik, and Marx (2006) found difficulties students may have in generating arguments: 1) Students sometimes do not collect the appropriate data from their investigation (McNeill \& Krajcik, 2007a). If the data contradict the students' theory, it is more likely that they will discount the data. 2) Students have difficulties understanding what counts as evidence and often rely on their personal views to draw conclusions (Hogan \& Maglienti, 2001; Sadler, 2004). They also have difficulties in using appropriate evidence (Sandoval, 2003) and providing sufficient evidence (Bell \& Linn, 2000; Erduran et al., 2004; Jimenez-Aleixandre et al., 2000; McNeill \& Krajcik, 2007a; Sadler, 2004). Another difficulty students face is in articulating and defending their claims (Sadler, 2004). 3) It is difficult for students to provide the necessary backing and warrants to support claims in their written arguments (Bell \& Linn, 2000).

\subsection{Teaching Argumentation}

Scholars claim that students should be taught argumentation when learning science (Simon et al., 2006). Duschl (2008) indicated five contributions of teaching argumentation in science classes: it requires metacognitive thinking, encourages the development of communication and critical thinking, strengthens the development of scientific literacy, encourages students to use scientific language, and supports the participation of students in practices of scientific culture and the development of epistemic criteria. Opportunities for students to learn how to engage in scientific argumentation in a productive manner are rare or frequently omitted from classroom practice. Teachers do not often encounter opportunities for construction of knowledge using argument-based pedagogical techniques (Newton, Driver, \& Osborne, 1999; Simon et al., 2006). The teachers themselves limit the activities that promote argumentation skills, because they are not skilled enough to develop activities in this field (Kaya, Erduran, \& Seda-Cetin, 2010). Teachers feel that they lack strategies for including arguments in their science teaching, even though they recognise the importance of argumentation (Glassner, 2009). Osborne, Erduran, Simon, and Monk (2001) proposed a set of activities to support the teaching of argumentation. The teachers were introduced to TAP and used its theoretical framework to introduce its application in the classroom. For example, they generated lesson materials that could structure students' writing of arguments by rephrasing claims, asking the students to state their claim, state the reasons for their claim (the data), state ideas that support their reasons (the warrant), and supply additional information that may support these ideas (the backings). When students are presented with similar processes through exposure to writing and discussion scaffolds, they learn how an inquiry is carried out, and this enables them to create evidence-based explanations based on their science investigations (Marzano, 2003). McNeill et al. (2006) defined scaffolds as supporting structures which are provided by people or tools in order to promote learning. The effects of teaching strategies that include different types of scaffolds for learning scientific inquiry were tested in a project carried out in chemistry lessons (McNeill \& Krajcik, 2007b; McNeill et al., 2006). Scaffolds that were context-specific were found to be more effective in the inquiry task, but only when the teachers supplied general scaffolds which they themselves provided for the scientific argumentation.

This study aims to examine the written arguments and the effect of the scaffolds on written arguments in bio-inquiry papers. The research was based on bio-inquiry papers written by two groups of students. In one group, the control group, the students received only written instructions on how to write the paper. In the second group, the experimental group, the students received scaffolds for writing arguments. The students learned how to write arguments in the context of different topics. The scaffolding was given in two parallel tracks: teaching content in biology classes and inquiry processes in the laboratory. 


\subsection{Research Questions}

1. What are the differences in components of the arguments (types and number) between the two groups (the control group and the experimental group)?

2. What are the differences in the quality and the levels of the arguments between the two groups?

Methodology

The research used a mixed methods approach. A content analysis of the bio-inquiry papers was conducted. The TAP model was used to examine the argument components (types and number). To examine the argument level, a tool that refers to the various components of an argument and is based on other tools was used (see Table 1) (Erduran et al., 2004; Osborne, Erduran, \& Simon, 2004; Simon \& Johnson, 2008). An argument that contains many components is a higher-level argument. When the two researchers did not agree on the encoding, the issue was discussed until a consensus was reached.

Table 1. The key to assessing the level of arguments (based on Erduran et al., 2004; Katchevich, Hofstein, \& Naaman, 2013; Osborne et al., 2004; Simon \& Johnson, 2008)

\begin{tabular}{l|l|l}
\hline The components & Symbol & Level \\
\hline Claim & C & 1 \\
\hline $\begin{array}{l}\text { Claim + Data or Claim + Warrant or } \\
\text { Claim + Backing }\end{array}$ & CD/CW/CB & 2 \\
\hline $\begin{array}{l}\text { Claim + Data + Warrant or } \\
\text { Claim + Data + Rebuttal or }\end{array}$ & CDW $\backslash$ CDR $\backslash$ CWR & 3 \\
Claim + Warrant + Rebuttal & & \\
\hline Claim + Data + Warrant + Backing & CDWB & 4 \\
\hline $\begin{array}{l}\text { Rebuttal that includes Claim + Data + Warrant or } \\
\text { Qualifier that includes Claim + Data + Warrant }\end{array}$ & CDWR $\backslash$ CDWQ & 5 \\
\hline
\end{tabular}

A scientific explanation expression was used as a warrant for analysing the argument's components, since students tend to explain the evidence which supports their arguments with scientific explanations based on their previous biology knowledge. An independent two-sample t-test was conducted to test whether the differences were significant between the two groups, meaning that the difference between them is not random but the result of the scaffolds.

The participants included 40 twelfth graders (15 boys and 25 girls) in the expanded biology program. Twenty students were included in the control group, and 20 students who received scaffolds for writing arguments were included in the experimental group. The students carried out their bio-inquiry in pairs, so that the sample included 10 papers for each group -the control group and experimental group. The papers dealt with different inquiry topics, such as the effect of density of plants on the vegetative growth of green onion, the effect of salinity on the germination of wheat seeds, the effect of wavelengths on the vegetative growth of wheat buds, the effect of auxin on the vegetative growth of wheat buds, the effect of a peppermint extract on the vegetative growth of wheat seeds, the effect of fertilizer on the vegetative growth of wheat, and the effect of chlorine bleach on the senescence of gerbera.

The same teacher taught the two groups. The intervention program which was implemented by the biology teacher included biology lessons and laboratory experiments. The students learned how to write an argument in the context of different topics that were learned in the class for example plant pollination. The instructions for writing conclusions and a discussion guided the students stage by stage: how to reach the relevant conclusions from the experimental results, connect them to biological knowledge, propose possible explanations for unexpected results or alternative explanations, and perform critical analysis of the conclusions.

\section{Results}

The components (types and number) of the written arguments of both groups were analysed according to the TAP model. The results are presented in Tables 2 and 3. 
Table 2. Components of the arguments in the bio-inquiry papers of the control group

\begin{tabular}{l|l|l|l|l|l|l|l|l|l}
\hline Paper no. & No. of proper questions & $\mathrm{C}$ & $\mathrm{D}$ & $\mathrm{W}$ & $\mathrm{B}$ & $\mathrm{Q}$ & $\mathrm{R}$ & $\mathrm{B}+\mathrm{W}+\mathrm{D}$ & $\begin{array}{l}\text { Ratio: } \\
\text { no. of arguments per claims }\end{array}$ \\
\hline 1 & 3 & 11 & 4 & 9 & 0 & 0 & 0 & 13 & 1.18 \\
\hline 2 & 4 & 7 & 2 & 6 & 7 & 1 & 1 & 15 & 2.14 \\
\hline 3 & 4 & 20 & 10 & 31 & 15 & 3 & 0 & 56 & 2.80 \\
\hline 4 & 2 & 9 & 3 & 11 & 14 & 1 & 0 & 28 & 3.11 \\
\hline 5 & 2 & 13 & 5 & 12 & 1 & 3 & 2 & 18 & 1.38 \\
\hline 6 & 2 & 9 & 5 & 1 & 4 & 2 & 0 & 10 & 1.11 \\
\hline 7 & 3 & 9 & 2 & 4 & 2 & 1 & 0 & 8 & 0.89 \\
\hline 8 & 1 & 13 & 5 & 8 & 4 & 3 & 1 & 17 & 1.31 \\
\hline 10 & 3 & 32 & 12 & 16 & 1 & 9 & 0 & 29 & 0.91 \\
\hline Total & 4 & 18 & 4 & 9 & 3 & 2 & 0 & 16 & 0.89 \\
\hline
\end{tabular}

A total of 141 claims were found in the papers of the control group, with a range of 7 to 32 claims. These students used 210 arguments, which included claims (C), data (D) and/or warrant (W) and/or backing (B). Each claim had an average of 1.48 arguments. The main component was a warrant, i.e. an explanation of the phenomenon, and it comprised $51 \%$ of the total arguments. The students used data (D) and backing (B) to the same extent. Little use was made of rebuttals (R). In 9 of the papers, the qualifier (Q) appears more than once.

Table 3. Components of the arguments in the bio-inquiry papers of the experimental group

\begin{tabular}{l|l|l|l|l|l|l|l|l|l}
\hline Paper no. & No. of proper questions & C & D & W & B & Q & R & B+W+D & $\begin{array}{l}\text { Ratio: } \\
\text { no. of arguments per } \\
\text { claims }\end{array}$ \\
\hline 1 & 1 & & & & & & & & \\
\hline 2 & 2 & 12 & 7 & 10 & 6 & 4 & 2 & 23 & 1.92 \\
\hline 3 & 1 & 11 & 5 & 9 & 7 & 2 & 1 & 21 & 1.91 \\
\hline 4 & 2 & 6 & 14 & 10 & 14 & 2 & 0 & 38 & 6.33 \\
\hline 5 & 3 & 5 & 14 & 1 & 2 & 0 & 3 & 17 & 3.40 \\
\hline 6 & 1 & 7 & 8 & 9 & 2 & 3 & 0 & 19 & 2.71 \\
\hline 7 & 2 & 3 & 3 & 7 & 4 & 2 & 0 & 14 & 4.67 \\
\hline 8 & 1 & 11 & 3 & 11 & 13 & 3 & 2 & 27 & 2.45 \\
\hline 9 & 1 & 10 & 6 & 7 & 8 & 1 & 0 & 21 & 2.10 \\
\hline 10 & 1 & 8 & 8 & 9 & 10 & 3 & 1 & 27 & 3.38 \\
\hline Total & 15 & 9 & 3 & 5 & 3 & 1 & 2 & 11 & 1.22 \\
\hline
\end{tabular}

A total of 82 claims were found in the papers of the experimental group. The claims ranged from 3 to 14. The students used 218 arguments, which included D and/or W and/or B. Each claim had an average of 2.66 arguments. Each of the argumentation components comprised approximately $30 \%$ of the total components. Q was used in all papers. Six papers used R.

A significant difference $(\alpha=0.05)$ was found between the number of claims in the papers of the experimental group and the papers of the control group (see Table 4). Students of the control group used a larger number of claims than students of the experimental group. The differences in use of argumentation and in the components of the arguments, such as D, W, and especially B, were not significant. A significant difference $(\alpha=0.01)$ was found between the groups: the experimental group had more arguments for each claim and used a larger number of high level argumentations (level 5) than the other group. There was no difference between the groups in claims without an argument (level 1). 
Table 4. Comparison between the components of the argument in papers of the experimental group and the control group

\begin{tabular}{|c|c|c|c|}
\hline $\begin{array}{l}\text { Mean of the components of the argument per paper and mean } \\
\text { standard deviation (SD) }\end{array}$ & $\begin{array}{l}\text { Control } \\
\text { Group }\end{array}$ & $\begin{array}{l}\text { Experimental } \\
\text { group }\end{array}$ & $\mathrm{t}$ \\
\hline $\begin{array}{l}\text { Claims Mean } \\
\text { Mean SD }\end{array}$ & $\begin{array}{l}14.1 \\
7.53\end{array}$ & $\begin{array}{l}8.2 \\
2.94\end{array}$ & $*_{2} .31$ \\
\hline $\begin{array}{l}\text { Data Mean } \\
\text { Mean SD }\end{array}$ & $\begin{array}{l}5.2 \\
3.29 \\
\end{array}$ & $\begin{array}{l}7.1 \\
4.12 \\
\end{array}$ & 0.16 \\
\hline $\begin{array}{l}\text { Warrants Mean } \\
\text { Mean SD }\end{array}$ & $\begin{array}{l}10.7 \\
8.27\end{array}$ & $\begin{array}{l}7.8 \\
2.97\end{array}$ & 1.04 \\
\hline $\begin{array}{l}\text { Backing Mean } \\
\text { Mean SD }\end{array}$ & $\begin{array}{l}5.1 \\
5.34 \\
\end{array}$ & $\begin{array}{l}6.9 \\
4.36 \\
\end{array}$ & 0.83 \\
\hline $\begin{array}{l}\text { DWB Mean } \\
\text { Mean SD }\end{array}$ & $\begin{array}{l}21 \\
14.06\end{array}$ & $\begin{array}{l}21.8 \\
7.6\end{array}$ & 0.16 \\
\hline $\begin{array}{l}\text { Ratio between number of arguments per claim Mean } \\
\text { Mean SD }\end{array}$ & $\begin{array}{l}1.6 \\
0.82 \\
\end{array}$ & $\begin{array}{l}3 \\
1.52 \\
\end{array}$ & $* * 2.63$ \\
\hline $\begin{array}{l}\text { High level argument Mean (5) } \\
\text { Mean SD }\end{array}$ & $\begin{array}{l}0.5 \\
0.8\end{array}$ & $\begin{array}{l}1.5 \\
0.7\end{array}$ & $* *-2.86$ \\
\hline $\begin{array}{l}\text { Low level argument Mean (1) } \\
\text { Mean SD }\end{array}$ & $\begin{array}{l}2.14 \\
1.68\end{array}$ & $\begin{array}{l}6.9 \\
3.77\end{array}$ & -0.82 \\
\hline
\end{tabular}

${ }^{*} \alpha=0.05 ;{ }^{* *} \alpha=0.01$

To examine the quality of written arguments and their strength we used the model presented in Table 1. The argument levels were examined according to the extent of their complexity and use of the argumentation components. Some examples of the different levels of the written arguments are presented below.

Level 1 - claim (C): "The higher the salt concentration, the longer the germination time will be."

Level 2 - claim + data (CD): "Plants that will be exposed to light waves from the ends of the spectrum (red and blue) will yield greater vegetative growth than those that will be exposed to light waves from the middle of the spectrum (C). The results of the experiment showed that the system that was illuminated with white light yielded the greatest growth. This was followed by the system that was illuminated with the yellow, the red, the blue light, and last, the system that was illuminated with green light (D)."

Level 3 - claim + data + warrant (CDW): "Peppermint contains substances that harm the activity of the organisms that live next to it $(\mathrm{C})$. The results of the experiment showed that as long as the peppermint extract is concentrated, the wheat does not survive (D). The wheat is affected by the peppermint, and as long as there is more peppermint it will not survive (W)."

Level 4 - claim + data + warrant + backing (CDWB): "Under conditions of mineral and water stress, vegetative growth is worse $(\mathrm{C})$. The results of the experiment show that this is indeed what happens. According to the results of the experiment, if we had tested an entire life cycle, we would have discovered that onions that grew without stress, i.e. with a sufficient amount of resources, would achieve greater vegetative growth than plants that grew under conditions of stress (D). There is also concern that some of the plants will not reach the end of their cycle, because under conditions of stress the plant is weakened and is more vulnerable to diseases and pests (B). It is important to note that the onion plants are especially sensitive to water stress compared with other domesticated plants. The onion's growth is affected even by weak water stress. This is also expressed in the roots system (W)."

Level 5 - claim + data + warrant + rebuttal (CDWR): "In addition to osmosis, salts have a toxic effect and directly harm the different biochemical processes that take place in the plant $(\mathrm{C})$. It is probable that osmosis is not the main cause for the non-germination of the seeds (R), because according to our examination, there is no real difference in the results between the various concentrations of the solutions (D). If, for example, the difference before and after immersion in solutions with the lower 
concentrations was higher than the differences at the high concentrations, we could know that the salts will block the entry of water (W)."

The distribution of the argument levels within the two groups is presented in Figure 1. The analysis was conducted according to Table 1:" The key to assessing the level of arguments".

The argument level of the students of the control group is in general lower than among students of the experimental group. A statistic significant was not found between the two groups, most likely due to the sample size.

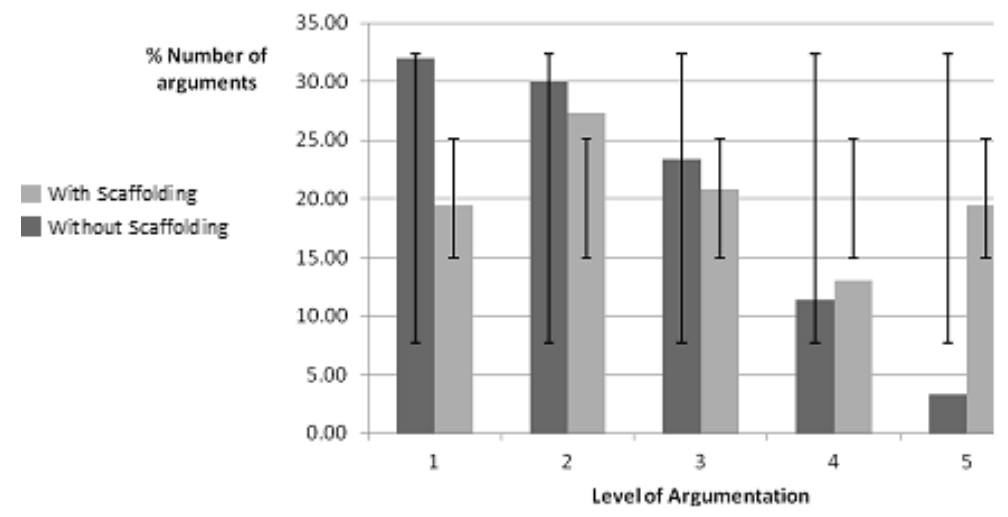

Figure 1. Distribution of the argument levels in the papers of the control group and the experimental group.

\section{Discussion}

The findings of this research support previous claims that inquiry has the potential to serve as a platform for formulating arguments (Olson \& Loucks-Horsley, 2000). This study shows that teaching argumentation encourages better writing of arguments. These findings reinforce previous studies in which it was claimed that argumentation skills can be acquired and that students who received scaffolds in the inquiry task which were context-specific demonstrated better mastery of the formulation of their answers and justification of their claims, and their achievements were higher than those of the control group (Katchevich et al., 2013; McNeill et al., 2006; McNeill \& Krajcik, 2007b; Osborne et al., 2001; Osborne et al., 2004). There are different ways to teach argumentation, including class discussions on dilemmas that arise on different issues in biology, such as human genetic issues (Zohar \& Nemet, 2002) and writing lab reports and inquiry papers. It is reasonable to assume that when teaching argumentation will encompass many activities in the science lessons, the students' argumentation skills will improve. The teacher in this research has taken two parallel steps: providing scaffolds for constructing written arguments in biology lessons regarding the content studied (plant pollination) and providing scaffolding in constructing arguments when conducting an experimental study in the laboratory. By rehearsing in parallel paths and strengthening the steps and components that were weak points in the students' arguments, the students showed better results in writing arguments. This is in congruence with the findings of Marzano (2003), that presenting students with similar processes through exposure to writing and discussion scaffolds enables them to develop the ability to construct argumentation based on their science investigations.

\section{Conclusion}

In this research, written explanations and content-specific scaffolds were used by the teacher for different argumentation components as in previous research to promote the construction of argumentations by the students (Sandoval, 2003). Content-specific scaffolds provide students with hints about the type of content knowledge they can use in their explanation. For example, Sandoval (2003) provided content scaffolds that support students in using the correct data in their explanation of natural selection. 
Similarly, to Erduran (2008, pp. 46-68), we chose Toulmin's method, which has guided and influenced researchers in the field and has made a great contribution to the methodology of studying school science argumentation. In addition to Toulmin's Argument Pattern (TAP), we also analyzed the argument level by a tool that refers to the various components of an argument and is based on other tools (Erduran et al., 2004; Osborne, Erduran, \& Simon, 2004; Simon \& Johnson, 2008). The various tools complemented each other and enabled pinpointing the differences between the two groups and also highlighted the difficulties faced by the students and gave the teacher an accurate picture of the writing process undergone by the students. As teachers' use of various tools for analysing arguments increases, so will they obtain a more accurate picture of the difficulties and will be able to build scaffolds. The students' ability to write arguments was reflected, for example, in components that were missing and the complexity of the argument. Students who received scaffolds used more claims that were based on arguments than students of the control group when writing their bio-inquiry paper. The scaffolds directed the students to write fewer claims with more arguments. No significant difference was found between the two groups in the use of the different types of arguments, but the ratio between arguments and claims indicates more reference to arguments among the students who received scaffolds. A significant difference was found between the number of claims of the experimental group and the control group. Furthermore, the experimental group made significantly more high-level arguments (level 5) than the students who did not receive scaffolds.

One of the limitations of the study was the fact that bio-inquiry papers were written on many different topics. Some of the topics are learned at length and in depth (for example, photosynthesis), whereas others are learned in brief (for example, competition). This may influence the number of arguments that a student presents in his or her paper. Another limitation stems from the variety of research questions. Different questions require a different level of arguments, and the level of arguments in an inquiry paper also depends on the research question for this particular bio-inquiry. Other limitations of this study include the small sample size (20 papers) and the short duration of the intervention (a few months). However, the fact that we found significant and consistent differences despite these limitations supports the strength of the effect.

\section{References}

1. Bell, P., \& Linn, M. (2000). Scientific arguments as learning artifacts: Designing for learning from the web with KIE. International Journal of Science Education, 22(8), 797-817.

2. Duschl, R. (2008). Science education in three-part harmony: Balancing conceptual, epistemic, and social. Review of Research in Education, 32(1), 268-291.

3. Efrat, N. (2002). Teaching biology by inquiry: difficulties, complex, emphases and teacher involvement. Ministry of Education (in Hebrew).

4. Erduran, S., \& Jimenez-Aleixandre, J. M. (2012). Research on argumentation in science education in Europe. In D. Jorde \& J. Dillon (Eds.), Science education research and practice in Europe: Retrospective and prospective (pp. 253-289). Rotterdam: Sense Publishers.

5. Erduran, S., \& Jimenez-Aleixandre, M. P. (Eds.) (2008). Argumentation in science education: Perspectives from classroom-based research. Dordrecht: Springer.

6. Erduran, S., Simon, S., \& Osborne, J. (2004). TAPing into argumentation: Developments in the application of Toulmin's argument pattern for studying science discourse. Science Education, 88(6), 915-933.

7. Glassner, A. (2009). Constructing and evaluating arguments in learning and teaching. In A. Glassner, A. BenDavid, \& E. Iger (Eds.), Development of high-order thinking: A literature review (pp.122-130). Jerusalem: Ministry of Education (Hebrew).

8. Hogan, K., \& Maglienti, M. (2001). Comparing the epistemological underpinnings of students and scientists' reasoning about conclusions. Journal of Research in Science Teaching, 38(6), 663-687.

9. Jimenez-Aleixandre, M. P., Rodriguez, A. B., \& Duschl, R. A. (2000). "Doing the lesson" or "Doing science": Arguments in high school genetics. Science Education, 84(6), 757-792.

10.Katchevich, D., Hofstein, A., \& Naaman, R. (2013). Argumentation in the chemistry laboratory: Inquiry and confirmatory experiments. Research in Science Education, 43(1), 317-345. 
11.Kaya, E., Erduran, S., \& Seda- Cetin, P. (2010). High school students' perceptions of argumentation. Procedia Social and Behavioral Sciences, 2(2), 3971-3975.

12.Marzano, R. J. (2003). What works in schools? Alexandria, VA: ASCD.

13.McNeill, K. L., \& Krajcik, J. (2007a). Middle school students' use of appropriate and inappropriate evidence in writing scientific explanations. In M. C. Lovett \& P. Shah (Eds.), Thinking with data: The Proceedings of the 33rd Carnegie Symposium on Cognition (pp. 233-265). Mahwah, NJ: Erlbaum.

14.McNeill, K. L., \& Krajcik, J. (2007b). Relationship between teacher instructional practices and curricular scaffolds in supporting students in writing scientific explanations. Paper presented at the annual meeting of the American Educational Research Association, Chicago.

15.McNeill, K. L., Lizotte, D. J., Krajcik, J., \& Marx, R. W. (2006). Supporting students' construction of scientific explanations by fading scaffolds in instructional materials. The Journal of the Learning Sciences, 15(2), 153-191.

16.Newton, P., Driver, R., \& Osborne, J. (1999). The place of argumentation in the pedagogy of school science. International Journal of Science Education, 21(5), 553-576.

17. Olson, S., \& Loucks-Horsley, S. (Eds.) (2000). Inquiry and the national science education standards: A guide for teaching and learning (Chapter 2, p. 18). Washington, DC: National Academy Press.

18. Osborne, J., Erduran, S., \& Simon, S. (2004). Enhancing the quality of argument in school science. Journal of Research in Science Teaching, 41(10), 994-1020.

19. Osborne, J. F., Erduran, S., Simon, S., \& Monk, M. (2001). Enhancing the quality of argument in school science. School Science Review, 82(301), 63-70.

20.Sadler, T. D. (2004). Informal reasoning regarding socio scientific issues: A critical review of research. Journal of Research in Science Teaching, 41(5), 513-536.

21.Sampson, V., \& Clark, D. (2008). Assessment of the ways students generate arguments in science education: Current perspectives and recommendations for future directions. Science Education, 92(3), 447-472.

22.Sandoval, W. (2003). Conceptual and epistemic aspects of students' scientific explanations. The Journal of the Learning Sciences, 12(1), 5-51.

23.Simon, S., Erduran, S., \& Osborne, J. (2006). Learning to teach argumentation: Research and development in the science classroom. International Journal of Science Education, 28(2-3), 235-260.

24.Simon, S., \& Johnson, S. (2008). Professional learning portfolios for argumentation in school science. International Journal of Science Education, 30(5), 669-688.

25.Toulmin, S. (1958). The uses of argument. Cambridge: Cambridge University Press.

26.Wilson, C. D., Taylor, J. A., Kowalski, S. M, \& Carlson, J. (2010). The relative effects and equity of inquirybased and commonplace science teaching on students' knowledge, reasoning, and argumentation. Journal of Research in Science Teaching, 47(3), 276-301.

27.Zohar, A., \& Nemet, F. (2002). Fostering students' knowledge and argumentation skills through dilemmas in human genetics. Journal of Research in Science Teaching, 39(1), 35-62. 